\title{
Alternate Substrates and Inhibitors of 1-Aminocyclopropane-1-carboxylic Acid Synthase
}

\author{
Shahrokh Khani-Oskouee, Kondareddiar Ramalingam, \\ Douglas Kalvin, and Ronald W. WoOdard
}

\begin{abstract}
Department of Medicinal Chemistry, College of Pharmacy, The University of Michigan,
\end{abstract} Ann Arbor, Michigan 48109-1065

Received June 4, 1986

\begin{abstract}
Structural analogs of (-)-S-adenosyl-L-methionine (SAM), in which the heterocyclic base was modified, were used to initiate studies to elucidate the active site conformation of the enzyme 1-aminocyclopropane-1-carboxylic acid (ACC) synthase, which was partially purified from Lycopersicon esculentum (tomato). These potential substrate analogs were screened for activity both as substrates and/or as inhibitors of ACC synthase. In general, ACC synthase was found to have a rather rigid specificity for the structural features of the natural substrate (SAM) in that only the purine base adenosine and adenosine analogs in which the $N^{6}$ nitrogen was modified were substrates. 1987 Academic Press. Inc.
\end{abstract}

\section{INTRODUCTION}

The conversion of (-)-S-adenosyl-L-methionine (SAM) to 1-aminocyclopropane-1-carboxylic acid (ACC) by ACC synthase, a pyridoxal phosphate (PLP)containing enzyme, has recently been shown to be the rate-limiting step in the biosynthesis of the important plant hormone ethylene $(I)$ in extracts of tomato fruits (2-5).

Preliminary studies on the crude enzyme preparation have shown an apparent $K_{m}$ of $13 \mu \mathrm{M}(4)$ and of $20 \mu \mathrm{M}$ (5) for SAM and a strict requirement for PLP (5). It is interesting to note that the previously reported (6) active-site-directed irreversible inhibitors of enzymes requiring PLP as a cofactor, such as aminoethoxyvinylglycine (AVG), aminooxyacetic acid (AOA), and rhizobitoxine, inhibit ACC synthase, but only in a reversible manner. The $K_{i}$ value for AOA was estimated to be $0.8 \mu \mathrm{M}$ (4) and for AVG $0.2 \mu \mathrm{M}$ (5). Several analogs of SAM, such as $S$-adenosylL-ethionine (SAE), methionine methylsulfonium salt, $S$-pentosyl-L-methionine, and $S$-adenosyl-L-homocysteine (SAH), have been tested as both substrate and

\footnotetext{
${ }^{1}$ Abbreviations used: SAM, (-)-S-adenosyl-L-methionine; ACC, 1-aminocyclopropane-1-carboxylic acid; $N^{6}(\mathrm{Me}) S A M, S$ - $N^{6}$-methyladenosyl-L-methionine; SIM, $S$-inosyl-L-methionine; SGM, $S$ guanosyl-L-methionine; SCM, $S$-cytidyl-L-methionine; SUM, $S$-uridyl-L-methionine; $N^{6}(\mathrm{Me})_{2}$-SAM, $S$ - $N^{6}, N^{6}$ dimethyladenosyl-L-methionine; $N^{6}(\mathrm{Bz}) \mathrm{SAM}, S$ - $N^{6}$-benzyladenosyl-L-methionine; SAH, $S$ adenosyl-L-homocysteine; Hepes, 4-(2-hydroxyethyl)-1-piperazineethane sulfonic acid; PLP, pyridoxalphosphate; AVG, aminoethoxyvinylglycine; AOA, aminooxyacetic acid; SAE, $S$-adenosyl-L-ethionine; HMPA, hexamethyl phosphoramide.
} 


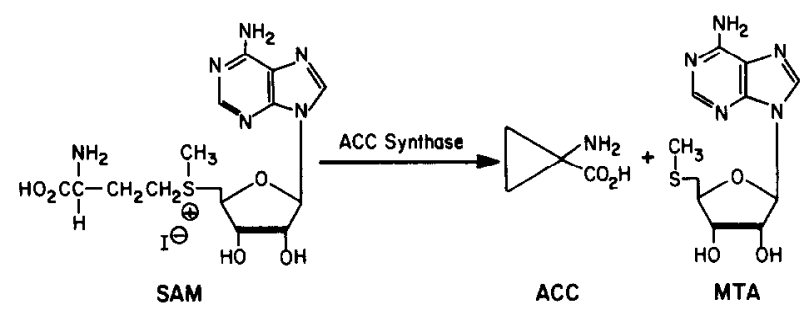

FIG. 1. Reaction catalyzed by 1-aminocyclopropane-1-carboxylate synthase.

inhibitor $(4,5)$. Of the analogs, only SAE served as an alternate substrate, with an apparent $K_{m}$ value of $6 \mu M$ and a $V_{\max } 30 \%$ that of SAM (4). The best SAM-like substrate inhibitor, SAH, had an $I_{50}=50 \mu \mathrm{M}(4)$. Recently, the naturally occurring antifungal antibiotics, Sinefungin, $\mathrm{A} 9145 \mathrm{C}$, and the synthetic nucleoside $5^{\prime}-S$ isobutyl-5'-dcoxythioadenosine, have been shown (7) to be inhibitors of ACC synthase. Sinefungin, the best inhibitor of the three, had an $I_{50}=25 \mu \mathrm{M}$ for ACC synthase isolated from red tomatoes.

Because the above data suggest that both the sulfonium function and the adenosine moiety (or maybe only an aromatic base) of the SAM molecule are essential components of an enzymatically active substrate for ACC synthase and since no studies to date have involved the testing of compounds which might serve as alternate substrates for ACC synthase, thereby allowing for the possibility of enhancing the ripening process, we decided to synthesize and study the effects of various analogs of SAM in which the base portion (adenine) of SAM is varied on the synthesis of ACC by ACC synthase.

\section{RESULTS AND DISCUSSION}

(-)-S-Adenosyl-L-methionine is a biological, ubiquitous molecule which may be viewed as being composed of three parts: an amino acid portion (methionine), a sugar portion (ribose), and an aromatic heterocyclic base portion (adenine). The study described here will present the results obtained when the adenine base portion was either modified or replaced with a different heterocycle.

The purine and pyrimidine analogs listed in Fig. 2 were synthesized by the routes outlined in Scheme 1. These analogs were tested as alternate substrates and/or inhibitors of ACC synthase. The appropriate biological data are summarized in Table 1.

Of the base modifications reported in this paper, only derivatization of the adenine ring's $N^{6}$ nitrogen led to compounds with catalytic activity. The replacement of the adenine ring with a pyrimidine base or the purine bases inosine or guanosine gave compounds with neither catalytic nor inhibitory activity.

Since the sulfonium center was generated by chemical alkylation of the SAH analogs with methyl iodide, the stereochemistry at the sulfur center should bc racemic. We have recently shown ( 8 ) that the apparent $K_{m}$ for synthetic ( \pm )-LSAM (supposedly racemic at the sulfur atom but actually 55:45(+)-L-SAM to 

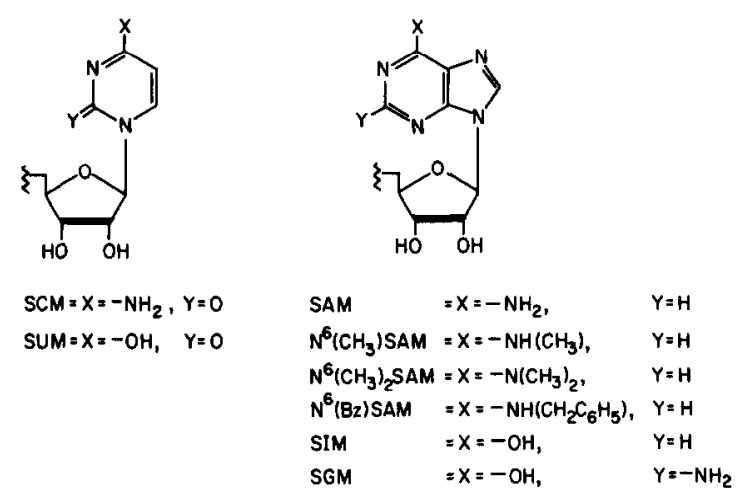

FIG. 2. Substitution pattern of various purines and pyrimidines tested.

(-)-L-SAM as determined by ${ }^{~} \mathrm{H}$ NMR) is $40 \pm 10 \mu \mathrm{M}$ and that the apparent $K_{m}$ for $(+)$-L-SAM (the unnatural stereoisomer at the sulfur center) is $15 \pm 5 \mu \mathrm{M}$. Therefore each analog tested contained, in a ratio of $\sim 55: 45$ unnatural to natural stereoisomer at the sulfur center, both a potentially enzymatically active isomer and a potentially enzymatically inactive isomer which may be inhibitory. It is, therefore, unlikely that the failure of the purine and pyrimidine SAM analogs to show any catalytic or inhibitory activity is simply due to the presence of a racemic sulfonium center.

The replacement of the 6-amino group of adenosine with a 6-hydroxyl group, inosine, led to a compound (SIM) inactive both as a substrate and as an inhibitor. This is rather surprising since both the amino and hydroxyl functions are capable of acting as hydrogen bond acceptors at the active site and both compounds are known to exist in solution in dynamic equilibrium between the preferred anti and syn conformation (9). Adding an amino function to the 2-position of the inosine portion of the SIM molecule, guanosine, generates a compound (SGM) inactive both as a substrate and as an inhibitor. Guanosine is also known to exist in solution in the favored anti conformation, as are most pyrimidines and purines other than those substituted in the 6- or 8-position, respectively, which generally prefer the syn conformation. Thus the lack of activity between SAM and SIM/ SGM toward ACC synthase cannot be explained simply on the basis of potential

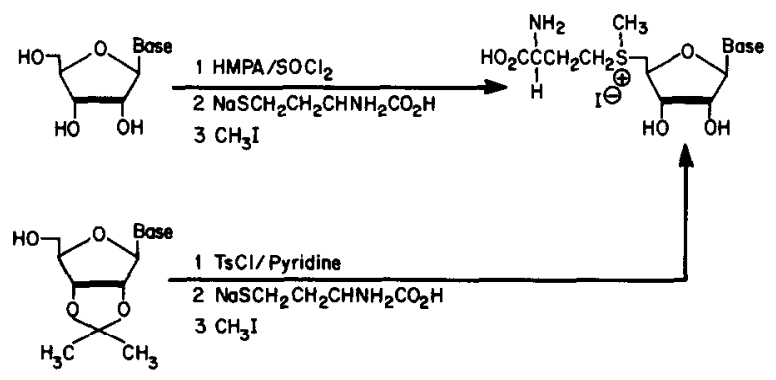

SCHEME 1. Synthetic route to the various ( \pm )-S-nucleosyl-L-methionines. 
TABLE 1

BIological Data for Various $S$-Nucleosyl-L-Methionines

\begin{tabular}{lccc}
\hline \multicolumn{1}{c}{ Compound } & $\begin{array}{c}V_{\max } \\
\text { (relative) }\end{array}$ & $\begin{array}{c}K_{m} \\
(\mu \mathrm{M})\end{array}$ & $\begin{array}{c}K_{i} \\
(\mu \mathrm{M})\end{array}$ \\
\hline$(-)$-L-SAM & 1 & $20 \pm 5$ & - \\
$( \pm)$-L-SAM & 1 & $40 \pm 10$ & - \\
$(+)$-L-SAM & - & - & $15 \pm 5$ \\
$( \pm)$-L-SAM & - & - & $70 \pm 20$ \\
$( \pm)-S-$-Inosyl-L-methionine & - & - & $>500$ \\
$( \pm)-S$-Guanosyl-L-methionine & - & - & $>500$ \\
$( \pm)-S-N^{6}-$ Methyladenosyl-L-methionine & 0.8 & $60 \pm 10$ & - \\
$( \pm)-S-N^{6}, N^{6}$-Dimethyladenosyl-L-methionine & 0.1 & $30 \pm 10$ & - \\
$( \pm)-S$ - $N^{6}-$ Benzyladenosyl-L-methionine & 0.25 & $5 \pm 2$ & - \\
$( \pm)-S$-Uridyl-L-methionine & - & - & $>500$ \\
$( \pm)-S$-Cytidyl-L-methioninc & - & - & $>500$ \\
\hline
\end{tabular}

changes in the base-sugar conformation since there are apparently no significant conformational differences among the three. The major difference, other than the obvious one between oxygen and nitrogen, among the three compounds is that in the case of inosine (SIM) and guanosine (SGM) the 6-hydroxyl group exists predominantly in the keto form (i.e., no hydrogen atom on the oxygen atom) and therefore can only serve as a hydrogen bond acceptor and not a hydrogen donor. In order to further explore the role of the hydrogen atoms attached to the hetero atom at position 6 in the purines, we synthesized the three nitrogen-substituted SAM analogs, $N^{6}(\mathrm{Me}) \mathrm{SAM}, S-N^{6}$-methyladenosyl-L-methionine; $N^{6}(\mathrm{Me})_{2} \mathrm{SAM}$, $S-N^{6}, N^{6}$-dimethyladenosyl-L-methionine, and $N^{6}(\mathrm{Bz}) \mathrm{SAM}, S-N^{6}$-benzyladenosyl-L-methionine.

As can be seen from Table 1, the $V_{\max }$ tends to diminish as the $N^{6}$ of the adenine ring becomes more substituted. The differences in the $V_{\max }$ values among SAM (1), $N^{6}(\mathrm{Me}) \mathrm{SAM}(0.8)$, and $N^{6}(\mathrm{Me})_{2} \mathrm{SAM}(0.1)$ are particularly interesting. These data along with those presented above suggest that the hydrogen atoms which are covalently bonded to the 6-amino group of the adenine portion may play an important role in the catalytic activity of SAM in the active site. This catalytic activity could presumably be through hydrogen bond donation of the hydrogen atoms at the $N^{6}$-position to an appropriate group in the active site. This seems feasible since in $N^{6}(\mathrm{Me})_{2} \mathrm{SAM}$ the nitrogen has no hydrogen atoms of its own to donate. In contrast, the inosine analog, SIM, which exists predominantly in the keto form, also could not act as a donor of hydrogens in hydrogen bond formations. However, both $N^{6}(\mathrm{Me})_{2} \mathrm{SAM}$ and SIM could both act as hydrogen bond acceptors. This could also explain some of the potential differences in the ability of SAM, SGM, and SIM to bind to the enzyme active site. One could argue that the differences in $V_{\max }$ occur with increasing substitution on the 6-amino group (i.e., increase in steric bulk at the $N^{6}$ nitrogen); however, $N^{6}(\mathrm{Bz}) \mathrm{SAM}$, monosubstituted at the $N^{6}$-position with a large group, appears to have a greater $V_{\max }$ than the disubstituted $\mathrm{N}^{6}(\mathrm{Me})_{2} \mathrm{SAM}$, indicating that the rate of catalysis may be inde- 
pendent of steric factors when comparing the analogs at hand. The $K_{m}$ values of the $N^{6}$-substituted SAM analogs, with the possible exception of $N^{6}(\mathrm{Bz}) \mathrm{SAM}$, are all equivalent, indicating little difference in their binding affinities.

Based on the ring specificity observed above it is not surprising that the replacement of the purine base with the pyrimidine bases uridine or cytidine led to compounds which were totally devoid of both catalytic or inhibitory activity.

It is interesting to note that AVG, AOA, and $S$-ribosyl-L-methionine are inhibitors of ACC synthase although the first two lack both the aromatic ring and the sugar portion and the latter one lacks the heterocyclic base. Apparently these inhibitors bind only to the amino acid-binding portion of the active site, which potentially could be separated from the binding site of the sugar and base moiety, or some other phenomenon is causing the lack of activity of ACC synthase.

Of the potential substrate analogs screened for activity both as substrates and/ or as inhibitors of ACC synthase only the purine base adenosine and adenosine analogs in which the $N^{6}$ nitrogen was modified were substrates. We therefore conclude that ACC synthase has a rather rigid specificity for the structural features of the natural substrate (SAM).

Studies are currently underway to evaluate the effect of changes in the nitrogen substitution pattern within the adenine ring system (i.e., various deazaadenosine analogs).

\section{EXPERIMENTAL PROCEDURE}

Materials. Organic, inorganic, and biological chemicals were procured from Aldrich Chemical Company, Alfa-Ventron Corporation, and Sigma Chemical Company, respectively. Tomatoes (Lycopersicon esculentum) in the "light pink" stage, vine-picked or purchased from a local vendor, were used to obtain the pericarp tissue for enzyme preparation.

Enzyme purification. The unpeeled pericarp tissue of tomatoes was chopped into small pieces and allowed to stand for $3 \mathrm{~h}$ at $25^{\circ} \mathrm{C}$. The tissue was homogenized in a glass-Teflon homogenizer with an equal volume of $100 \mathrm{~mm}$ Hepes (pH 8.5), 4 $\mathrm{mm}$ dithiothreitol, $0.5 \mu \mathrm{M}$ pyridoxal phosphate, and 5\% polyvinylpyrrolidone $(\mathrm{w} / \mathrm{v})$. The preparation was pressed through several layers of cheesecloth and centrifuged at $15,000 \mathrm{~g}$ for $30 \mathrm{~min}$. The supernatant was fractionated by precipitation with solid ammonium sulfate. The fraction precipitating between 40 and $90 \%$ (pH 7.2) was dialyzed overnight against $2 \mathrm{~mm}$ Hepes (pH 8.5) containing $0.1 \mathrm{~mm}$ dithiothreitol and $0.2 \mu \mathrm{M}$ pyridoxal phosphate, and the dialyzed enyzme was used without further purification.

Enzyme assay. A modification of the assay previously described was employed to analyze the ACC synthase activity (10). The assay consisted of $50 \mathrm{nmol}$ of SAM or increasing concentrations of alternate substrates, $30 \mu \mathrm{mol}$ of $\mathrm{K}$-Hepes, $\mathrm{pH} 8.5$, and $700 \mu \mathrm{l}$ of the $40-90 \%\left(\mathrm{NH}_{4}\right)_{2} \mathrm{SO}_{4} \mathrm{ppt}$ dialyzed enzyme preparation in a total volume of $800 \mu \mathrm{l}$. After $15 \mathrm{~min}$ to $3 \mathrm{~h}$ at $30^{\circ} \mathrm{C}$ the reaction mixtures were cooled in ice to $4^{\circ} \mathrm{C}, 100 \mu \mathrm{l}$ of $10 \mathrm{mM} \mathrm{HgCl}_{2}$ was added to each tube, the volumes were adjusted to $1 \mathrm{ml}$ for each mixture, and the tubes were capped with rubber septa, 
vortexed, and returned to the ice bath. To analyze the amount of ACC formed in each tube, the ACC was converted to ethylene by the addition of $100 \mu \mathrm{l}$ of $\mathrm{NaOCl}$ $(5 \%)-\mathrm{NaOH}(10 \mathrm{~N})$ mixture $(2: 1 \mathrm{v} / \mathrm{v})$. After the addition of the bleach solution, the tube was vortexed for $30 \mathrm{~s}$ and a 1-ml sample from the gas phase was withdrawn through the septum cap for the determination of ethylene by a gas chromatograph equipped with a flame ionization detector. A column $(45 \times 0.64 \mathrm{~cm})$ of $60-80$ mesh of $\mathrm{Al}_{2} \mathrm{O}_{3}$, at $90^{\circ} \mathrm{C}$, with helium as carrier gave a retention time of $25 \mathrm{~s}$ for ethylene. To determine the efficiency of the conversion of ACC to ethylene, a known amount of ACC (10 nmol) was added as an internal standard to another similarly incubated reaction mixture and converted to ethylene as described above. Yields of ethylene were consistently $80-90 \%$, and ethylene obtained from blank samples containing no substrate or enzyme was less than $1 \%$ of that obtained with enzyme. Protein was determined according to Bradford (11).

Enzyme inhibition. ACC synthase prepared from light pink tomatoes with a specific activity of $1.8 \mathrm{nmol} / \mathrm{mg}$ protein/h was incubated with various amounts of inhibitor and the enzyme activity assayed as described above with (-)-L-SAM.

\section{Syntheses}

5'-Chloro-5'-deoxynucleoside. These derivatives of the adenosine analogs were prepared according to the procedure of Kikugawa and Ichino (12) as follows: To a stirred solution of $10 \mathrm{ml}$ of thionyl chloride in $10 \mathrm{ml}$ of hexamethyl phosphoramide (HMPA) was added the solid unprotected nucleoside $(4.1 \mathrm{mmol})$. After stirring at room temperature for $18 \mathrm{~h}$, the solution was loaded directly onto a Dowex 50-X 4200 column $\left(\mathrm{NH}_{4}^{+}\right.$form) $(125 \mathrm{ml})$ and washed with water to remove the HMPA. The products were eluted with $1.0 \mathrm{M} \mathrm{NH}_{4} \mathrm{OH}$ and the fractions containing products were neutralized with $1.0 \mathrm{~N} \mathrm{HCl}$ and the water was removed under reduced pressure. The solid residues were recrystallized from the appropriate solvent and all physical data are in agreement with literature values.

$2^{\prime}, 3$ '-Isopropylidene-5'-O-toluene-p-sulfonylnucleoside. These derivatives of guanosine, inosine, and uridine were prepared by the procedure of Borchardt $e t$ al. (13) as follows: To a stirred solution of $2.33 \mathrm{mmol}$ of the $2^{\prime}, 3^{\prime}$-isopropylidene nucleoside in $20 \mathrm{ml}$ of dry pyridine, freshly distilled from barium oxide, at $0-5^{\circ} \mathrm{C}$ (ice-salt bath), was added all at once $2.5 \mathrm{mmol}$ of freshly recrystallized $p$-toluenesulfonyl chloride. The mixture was stirred over night $(12 \mathrm{~h})$ at room temperature. The pyridine was removed under reduced pressure and the residue taken up in water. The solution was extracted with $\mathrm{CHCl}_{3}(3 \times 50 \mathrm{ml})$ and the combined $\mathrm{CHCl}_{3}$ extracts were extracted with $\mathrm{H}_{2} \mathrm{O}$ and then $5 \% \mathrm{NaHCO}_{3}$. The organic layer was dried over $\mathrm{MgSO}_{4}$ and the $\mathrm{CHCl}_{3}$ removed under reduced pressure (water aspirator) to give a tacky solid which was crystallized from $\mathrm{CHCl}_{3}$ hexanes. All physical data for these compounds are in agreement with literature values.

$S$-Nucleosyl-L-homocysteine. A suspension of the $5^{\prime}$-chloro-5'-deoxynucleoside or the $2^{\prime}, 3^{\prime}$-isopropylidene-5'-O-toluene- $p$-sulfonyl nucleoside $(2.0 \mathrm{mmol})$, potassium iodide $(10 \mathrm{mg})$, and the sodium salt of $\mathrm{L}$-homocysteine $(2.5 \mathrm{mmol})$ was heated to reflux in water $(7 \mathrm{ml})$ for $2 \mathrm{~h}$. The reaction mixture became clear, and TLC (Avicel $\mathrm{F}, 250 \mu \mathrm{m}, \mathrm{CHCl}_{3}-\mathrm{EtOH}-\mathrm{H}_{2} \mathrm{O}, 3: 2: 0.5$ ) showed the absence of any 5'- 
chloro-5'-deoxynucleoside or 5'-tosylate-5'-deoxynucleoside. The mixture was cooled and made acidic with $1 \mathrm{~N} \mathrm{HCl}$. In addition to adjusting the $\mathrm{pH}$ of the reaction mixture this also serves to remove the isopropylidene-protecting group. The solution was then applied directly to a column of Dowex 50-X 4-200 $\left(\mathrm{NH}_{4}^{+}\right.$ form) $(125 \mathrm{ml})$. The column was washed thoroughly with water $(200 \mathrm{ml})$ and then eluted with $1 \mathrm{~N} \mathrm{NH}_{4} \mathrm{OH}$. The eluate was evaporated to a small volume in vacuo and lyophilized. The products were recrystallized from the appropriate solvents. Yields averaged $45-80 \%(14)$.

$( \pm)-S$-Nucleosyl-L-methionine. $S$-Nucleosyl-L-homocysteine $(25 \mathrm{mg})$ was added to a stirred solution of a $1: 1(\mathrm{v} / \mathrm{v})$ mixture of acetic acid: formic acid $(1 \mathrm{ml})$. To this mixture was added $0.1 \mathrm{ml}$ of methyl iodide and then $25 \mathrm{mg}$ of silver acetate. The mixture was stirred in a foil-wrapped flask at room temperature for $4 \mathrm{~h}$. The mixture was centrifuged and the supernatant extracted with diethyl ether (15). The aqueous layer was then applied to a $\mathrm{C}-18$ reversed-phased, low-pressure column. The $( \pm)-S$-nucleosyl-L-methionines eluted immediately after the void volume. The appropriate fractions were lyophilized. The purity was checked by HPLC (Whatman Particil PXS 10/25 SCX); buffer $0.1 \mathrm{M} \mathrm{NH}_{4} \mathrm{PO}_{4}, \mathrm{pH}=3.5$; flow rate $3.5 \mathrm{ml} / \mathrm{min}$; uv detector ( $260 \mathrm{~nm}$ wavelength monitor); sample retention times (ml) were as follows: MTA 11.3, SAH 7.5, and SAM 50. In all cases the ( \pm )-Snucleosyl-L-methionines eluted last. ${ }^{1} \mathrm{H}$ NMR spectra taken at $270 \mathrm{MHz}$ on an IBM WP 270 SY showed two methyl signals at $\delta \cong 2.9$ (sulfonium methyl group resonance for the unnatural stereoisomer at the sulfur center) and 3.0 (sulfonium methyl group resonance for the natural stereoisomer at the sulfur center) for each of the SAM analogs prepared (16).

These synthetic sequences are summarized in Scheme 1 and all compounds exhibited the physical and spectral characteristics in accordance with the reported values.

\section{ACKNOWLEDGMENT}

This work was supported by the U.S. Public Health Service through Research Grant GM 30097.

\section{REFERENCES}

1. Abeles, F. B. (1973) in Ethylene in Plant Biology, Academic Press, New York.

2. YANG, S. F. (1980) Hortscience 15, 238-245.

3. Apelbaum, A., Burgoon, A. C., Anderson, J. D., Solomon, T., And Lieberman, M. (1981) Plant Physiol. 67, 74-79.

4. Boller, T., Herner, R. C., ANd Kende, H. (1979) Planta 145, 293-303.

5. YU, Y. B., Adams, D. O., ANd Yang, S. F. (1979) Arch. Biochem. Biophys. 198, 280-286.

6. RANDo, R. R. (1978) in Principles of Catalytic Enzyme Inhibition in Enzyme-Activated Irreversible Inhibitors, Elsevier, New York.

7. ICekson, I., AND Apelbaum, A. (1983) Biochem. Biophys. Res. Commun. 113, 586-591.

8. Khani-Oskouee, S., Jones, J. P., ANd Woodard, R. W. (1984) Biochem. Biophys. Res. Commun. 121, 181-187.

9. SAenger, W. (1979) in Nucleoside Analogues, Chemistry, Biology, and Medical Applications 
(Walker, R. T., De Clereq, E., and Eckstein, F., Eds.), p. 4 and references contained therein, Plenum, New York/London.

10. Lizada, M. C. C., And Yang, S. F. (1979) Anal. Biochem. 100, 140-145.

11. BRADFORD, M. M. (1976) Anal. Biochem. 72, 248-254.

12. Kikugawa, K., AND ICHINo, M. (1971) Tetrahedron Lett, pp. 87-90.

13. Borchardt, R. T., Huber, J. A., ANd Wu, Y. S. (1974) J. Med. Chem. 17, 868-873.

14. Ramalingam, K., and Woodard, R. W. (1984) J. Org. Chem. 49, 1291-1293.

15. Pankaskie, M., and Monem, M. A. (1980) J. Med. Chem. 23, 121-127.

16. Stolowitz, M. L., AND Minch, M. J. (1981) J. Amer. Chem. Soc. 103, 6015-6019. 